\title{
MULTIVARIABLE AND DISTRIBUTED LQG CONTROL OF A WATER DELIVERY CANAL ${ }^{1}$
}

\author{
João M. Lemos ${ }^{2} \quad$ Luís F. Pinto $^{3} \quad$ Luís M. Rato $^{4} \quad$ Manuel Rijo $^{5}$
}

\section{ABSTRACT}

This work addresses the problem of the development of a distributed LQG controller for a water delivery canal. The control structure proposed relies on a set of LQG control agents interconnected through a communication network. Each of these local control agents controls a canal reach made of a pool and the corresponding downstream gate and receives information (output signal and control moves) only from the corresponding canal reach and the ones that are adjacent to it. An algorithm is proposed to achieve coordinated action of the different local control agents. This distributed control structure is compared with centralized multivariable LQG control. Several aspects with incidence on performance are addressed, including the modification of the quadratic cost to ensure a constraint on closed-loop poles, the use of a nonlinear filter to limit noise effects and the impact of a quantization commonly forced in gate position. Experimental results obtained in a pilot canal are presented.

Keywords: Water delivery canal, canal control, distributed control, multivariable control, LQG. 